\title{
Development and Validation of Implicit Measures of Emotional Intelligence Attributes
}

\author{
Ricardo R. Brooks \\ University at Albany, State University of New York \\ Louis L. Oberdiear \\ Missouri State University \\ Donald L. Fischer \\ Missouri State University
}

\begin{abstract}
Emotional intelligence is important for success in a wide range of social and professional roles. Interest in EI has spawned a debate about whether EI should be defined and measured as a set of abilities or as a set of dispositional self-perceptions, the latter being typically assessed with self-report measures that are susceptible to inaccurate self-knowledge and impression management artifacts. This research used Implicit Association Test procedures to develop measures of emotional intelligence and examined their construct validity using a multitrait-multimethod design. The results of confirmatory factor analyses of nested latent trait models provided evidence of convergent and discriminant validity.
\end{abstract}

Keywords: emotional intelligence. implicit association test, construct validity, multitrait-multimethod

\section{INTRODUCTION}

Emotional Intelligence (EI) is a construct that has attracted interest from both researchers and practitioners in the decades since Goleman's (1995) claim that it plays an important role for success in a wide range of social and professional roles (Bowen, 2019; Lievens \& Chan, 2010). Along with popularity has come criticism and controversy regarding the construct's definition and measurement (Cherniss, 2010). In part, this controversy relates to whether EI should be conceptualized as a set of cognitive abilities (Mayer, Salovey, \& Caruso, 2004), a set of dispositional self-perceptions (Petrides, 2011), or a combination of both (Goleman, 1995). The dispositional model characterizes EI as a "constellation of behavioral dispositions and self-perceptions concerning one's ability to recognize, process, and utilize emotion-laden information" (Petrides \& Furnham, 2003, p. 278) - a constellation which is located at the lower levels of personality hierarchies. As such, trait-EI represents the emotional self-efficacy component of the self-concept.

Self-report measures of self-concept can be described as explicit measures in that they ask one to describe how one consciously thinks of oneself (Wilson \& Dunn, 2004). This self-descriptive task allows time for the person to thoughtfully deliberate before responding. Kahneman (2011) describes the cognitive processes that underlie these tasks as "thinking slow" (System 2), which he contrasts with "thinking fast" 
(System 1). The latter involves automatic associations and implicit cognitive processes which operate outside one's conscious awareness. Implicit cognition is defined by Greenwald and Banaji (1995) as cognitions, feelings and evaluations that are not necessarily available to conscious awareness, conscious control, conscious intention, or self-reflection. They say the "signature of implicit cognition is that traces of past experiences affect some performance - even though the influential earlier experience is not remembered in the usual sense - that is, it is unavailable to self-report or introspection" (p. 4-5). Unlike explicit measures, the Implicit Association Test (IAT; Greenwald et al, 1998) involves reaction times on classification tasks that target the cognitive processes related to "thinking fast" (System 1), thus depriving one of the opportunity to thoughtfully deliberate before responding.

There has been much discussion about the relationship between implicit and explicit measures of cognitive knowledge structures, like those involving social attitudes, personality traits, and self-concepts (Fazio \& Olsen, 2003; Greenwald et al., 2002; Schnabel et al., 2008). Several hypotheses have been offered as to why dissociation and association between implicit and explicit measures of psychological constructs are observed. It has been suggested that discordance between explicit and implicit measures can occur when individuals are reluctant to admit, explicitly, to the tendency revealed by the implicit measure. In other words, individuals can be motivated to distort or disguise when asked to report how they feel and what they think (Wilson \& Dunn, 2004). It has also been suggested that dissociation may occur because individuals lack introspective insight and accurate self-knowledge (Greenwald et al., 2002). Wilson's model of dual attitudes (Wilson, Lindsey \& Schooler, 2000) proposes that neither implicit nor explicit attitudes are "bona fide" or "true," but rather each co-exists and directs behavior. Petrides (2011) makes a similar argument for ability and trait conceptualizations of emotional intelligence - both represent ways in which individuals differ. At this point research should be discovering how these differences can be measured and how these differences manifest in behavior that people and organizations care about.

The purpose of this research was to develop psychometrically sound implicit measures of attributes related to trait-EI and to explore how these are related to explicit measures of these attributes. Confirmatory factor analytic (CFA) procedures were used to evaluate a set of nested latent trait models in a multitraitmultimethod (MTMM) design (Campbell \& Fiske, 1959) and test hypotheses involving the convergent and discriminant validity of the measures.

\section{METHOD}

\section{Sample}

A sample of 701 participants was recruited using Amazon's Mechanical Turk (MTurk) system. Participants were compensated at a rate slightly above the average rate for the type of Human Intelligence Task (HIT) the study involved, at the time the data were collected.

\section{Explicit Measures}

Sixty-four items from the NEO-PI-R (Costa \& McCrae, 1992) provided scores on eight facet scales that theory and research (Petrides et al., 2007) suggest are related to the four components of Goleman's (2001) model of EI (see Figure 1). 
FIGURE 1

GOLEMAN'S (2001) TWO-BY-TWO MODEL OF EMOTIONAL COMPETENCIES

\begin{tabular}{|c|c|c|}
\hline & Self (Personal Competence) & Other (Social Competence) \\
\hline $\begin{array}{l}\text { Emotional } \\
\text { Recognition }\end{array}$ & $\begin{array}{l}\text { Self-awareness } \\
\text { - Emotional self-awareness } \\
\text { - Accurate self-assessment } \\
\text { - Self-confidence }\end{array}$ & $\begin{array}{l}\text { Social Awareness } \\
\text { - Empathy } \\
\text { - Service orientation } \\
\text { - Organizational awareness }\end{array}$ \\
\hline $\begin{array}{l}\text { Emotional } \\
\text { Regulation }\end{array}$ & $\begin{array}{l}\text { Self-management } \\
\text { - Self-control } \\
\text { - Trustworthiness } \\
\text { - } \text { Conscientiousness }\end{array}$ & $\begin{array}{l}\text { Relationship Management } \\
\text { - Communication } \\
\text { - Conflict management } \\
\text { - Teamwork and Collaboration }\end{array}$ \\
\hline
\end{tabular}

Two facet scales were selected for each of Goleman's four EI competencies: O3-Feelings and E6Positive Emotions (Self-awareness); N4-Self Conscious and N6-Vulnerable (Self-management); A3Altruism and A6-Tenderminded (Social Awareness); E2-Gregarious and E3-Assertive (Relationship Management). Each facet scale contained eight items. The short form of the TEIQue (v1.50; Petrides \& Furnham, 2001) provided four factor scales related to trait-EI: Emotionality, Sociability, Self-control, and Well Being. The factor scales are composites of 15 more basic scales which, in turn, are composed of responses to the measure's 30 items. Although the four TEIQue factors do not map onto the four components of Goleman's model in an isomorphic manner, each of Goleman's competencies is theoretically related to one or more of the TEIQue factors. These relationships are displayed in the CFA model labeled Model 1 in Figure 2.

FIGURE 2

\section{CFA MODEL 1: TWO FREELY CORRELATED METHOD FACTORS AND FOUR FREELY CORRELATED TRAIT FACTORS}

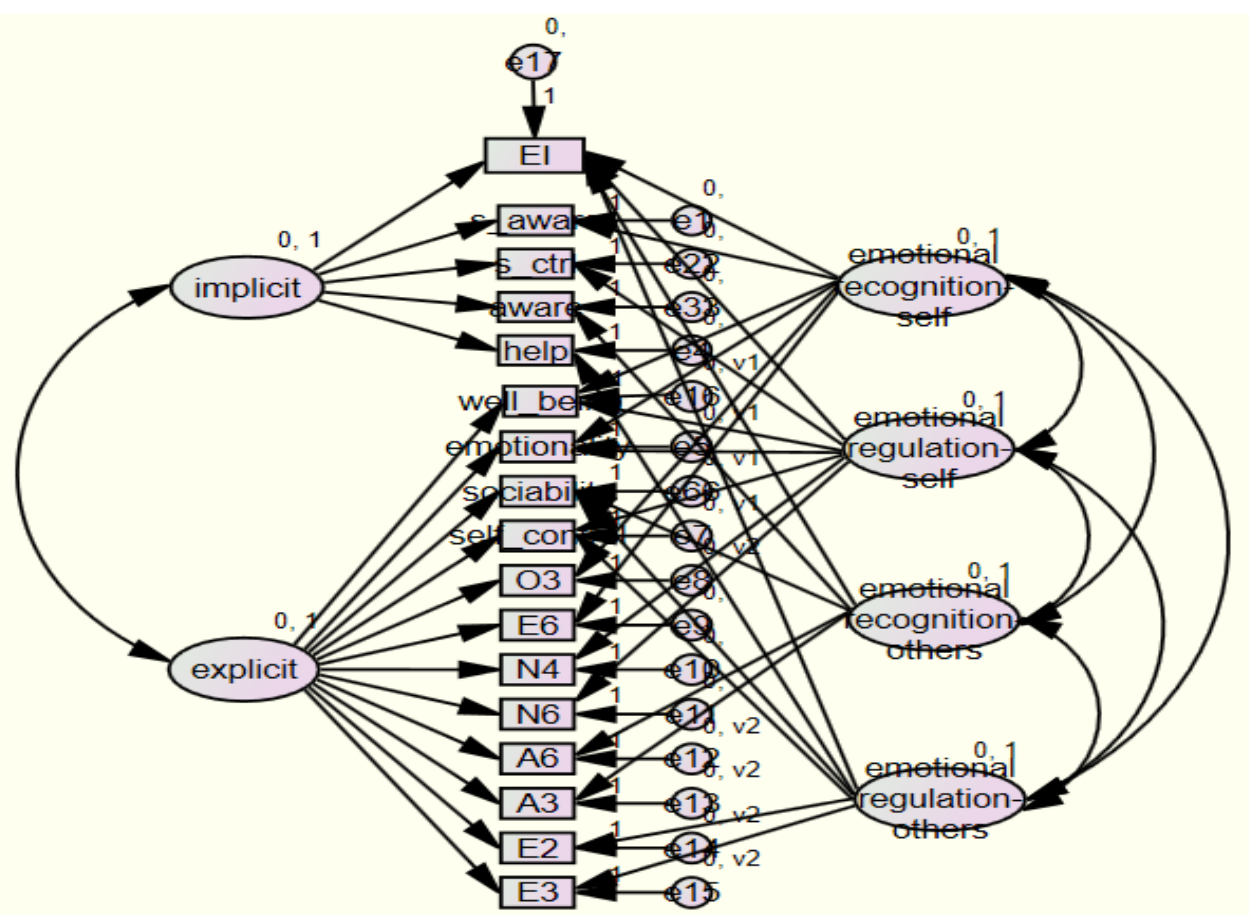




\section{Implicit Measures}

Oberdiear et al. (2016) developed four non-bipolar IATs by pairing attributes that are strongly associated with EI (e.g., relationship management) with attributes that are weakly associated with EI (e.g., physical strength). In accord with Schnabel et al. (2008), the stimuli associated with the attributes were balanced with respect to an evaluative dimension, in much the same way that forced-choice self-report measures match items according to their social desirability. Although CFA analyses of nested models in a MTMM design provided some support for the construct validity of the measures, there were problems with the psychometric properties of the implicit measures. Two of the IATs had internal consistency coefficients well below the range considered adequate (e.g., .45 and .58) and only two of the IATs had a significant loading on the corresponding latent EI trait factor. The current study relied on guidelines provided by Lane et al. (2007) to improve upon the psychometric properties of the IATs developed by Oberdiear et al. (2016). All IATs used the standard seven block procedure and D-scoring method described by Greenwald et al. (2003). However, rather than using a self-referent dichotomy (me versus not-me) for the target categories, pilot studies suggested that pairing the target attributes (EI versus non-EI) with the standard evaluative categories (good versus bad) would produce IATs with lower stimulus misclassification error rates and greater internal consistency coefficients. As such, these measures tap into the values that anchor one's implicit self-concept - i.e., larger IAT effects reflect stronger automatic associations of the EI constructs in one's self-concept with "good," relative to the non-EI attribute with which it is paired.

In accord with Oberdiear et al. (2016), four IATs were constructed, one for each component of Goleman's (2001) two-by-two model (see Figure 1): Self-Management (regulation of one's own emotions), Self-Awareness (recognition of one's own emotions), Social Awareness (recognition of others' emotions) and Relationship Management (regulation of others' emotions). A fifth global EI IAT was constructed by using a single stimulus item from each of the four components. The mean classification error rates, score variances, and internal consistency coefficients for various alternative category labels and word stimuli were evaluated in a series of pilot tests before a final set of labels and stimuli were chosen. Unlike the Oberdiear non-bipolar IATs, each of the five EI attributes was paired with a common oppositional attribute (egotism). In order to create valance-balanced IATs and avoid confounding self-esteem with the targeted attributes, stimuli were selected so that the mean valence ratings from research team members $(N=8)$ were approximately equal across the attribute categories. The label for the contrasting attribute category was also changed (from egotism to individualism) to achieve a better match with the valence ratings for the EI category labels. Table 1 and Table 2 display the category labels and stimuli for all IATs. ${ }^{1}$

TABLE 1

\section{CATEGORY LABELS AND WORD STIMULI FOR GOLEMAN'S FOUR EI ATTRIBUTES}

\begin{tabular}{llll}
\hline Self-Management & Self-Awareness & Relationship Management & Social Awareness \\
\hline Together & Introspective & Supportive & Perceptive \\
Steady & Reflective & Caring & Observant \\
Composed & Insightful & Attentive & Sensing \\
Controlled & Intuitive & Understanding & Mindful \\
\hline
\end{tabular}

TABLE 2

\section{CATEGORY LABELS AND WORD STIMULI FOR GLOBAL TRAIT-EI AND NON-EI ATTRIBUTES}

\begin{tabular}{ll}
\hline Emotional Intelligence & Individualism \\
\hline Relationships & Legacy \\
Empathy & Prestige \\
Poise & Reputation \\
Adaptability & Money \\
\hline
\end{tabular}




\section{Procedure}

The HIT posted on MTurk took about 45 minutes to complete and consisted of a set of demographic questions, five IATs, and twelve explicit scales. The order in which the measures were administered was fixed: demographic items, followed by the IATs, the NEO facet scales, and the TEIQue items.

\section{RESULTS}

Of the 701 MTurk workers who participated in the study, only 326 completed all measures within the allotted time constraints (two hours). Participants were further screened based on the validity of their IAT scores. Following guidelines provided by Greenwald and others, those with misclassification error rates in excess of $25 \%$ were considered invalid. Pilot data suggested that mean error rates for subjects who were conscientiously engaged in the IAT sorting tasks averaged about $10 \%$, with well over $90 \%$ of pilot subjects having mean error rates below $25 \%$. The final sample $(\mathrm{N}=175)$ was $65 \%$ female, with a mean age of 40.2 and mean of 18.1 years of employment. Three quarters of the sample self-identified as United States citizens. Sample racial demographics were as follows: 1\% American Indian or Alaskan Native, 3.5\% Black or African American, 3.5\% Two or More racial groups, 5\% Hispanic or Latino, 24\% Asian and 63\% nonHispanic White. Tables 3 and 4 contain descriptive statistics for study variables based on the final sample. Of particular interest are the internal consistency coefficients for the five IATs - all fall within the range of "acceptable" according to Nunnally's (1978) recommendations.

TABLE 3

DESCRIPTIVE STATISTICS FOR STUDY VARIABLES

\begin{tabular}{lllllll}
\hline Variables & N & Min & Max & Mean & SD & Alpha \\
\hline Implicit Measures & & & & & & \\
$\quad$ Social Awareness & 175 & -.47 & 1.18 & .33 & .32 & .76 \\
Relationship Mgt & 175 & -.41 & 1.35 & .32 & .31 & .73 \\
Self-Awareness & 175 & -.70 & 1.33 & .27 & .31 & .74 \\
Self-Management & 175 & -.45 & 1.11 & .27 & .29 & .76 \\
Global EI & 175 & -.77 & 1.24 & .34 & .40 & .86 \\
Explicit Measures & & & & & & \\
N4-SelfConscious & 175 & 8 & 40 & 23.03 & 5.76 & .79 \\
N6-Vulnerable & 175 & 8 & 36 & 18.64 & 5.73 & .86 \\
E2-Gregarious & 175 & 8 & 35 & 22.18 & 6.38 & .84 \\
E3-Assertive & 175 & 11 & 36 & 23.25 & 5.14 & .77 \\
E6-Pos. Emotions & 175 & 14 & 38 & 27.94 & 5.23 & .77 \\
O3-Feelings & 175 & 19 & 40 & 30.14 & 4.35 & .74 \\
A3-Altruism & 175 & 17 & 40 & 31.74 & 4.48 & .78 \\
A6-TenderMinded & 175 & 16 & 40 & 30.53 & 4.22 & .65 \\
Sociability & 174 & 1.50 & 7.00 & 4.73 & .85 & .75 \\
Self-Control & 174 & 2.00 & 7.00 & 4.71 & .98 & .79 \\
Emotionality & 174 & 3.25 & 7.00 & 5.12 & .89 & .81 \\
Well-Being & 174 & 2.50 & 7.00 & 5.19 & .91 & .78 \\
\hline
\end{tabular}




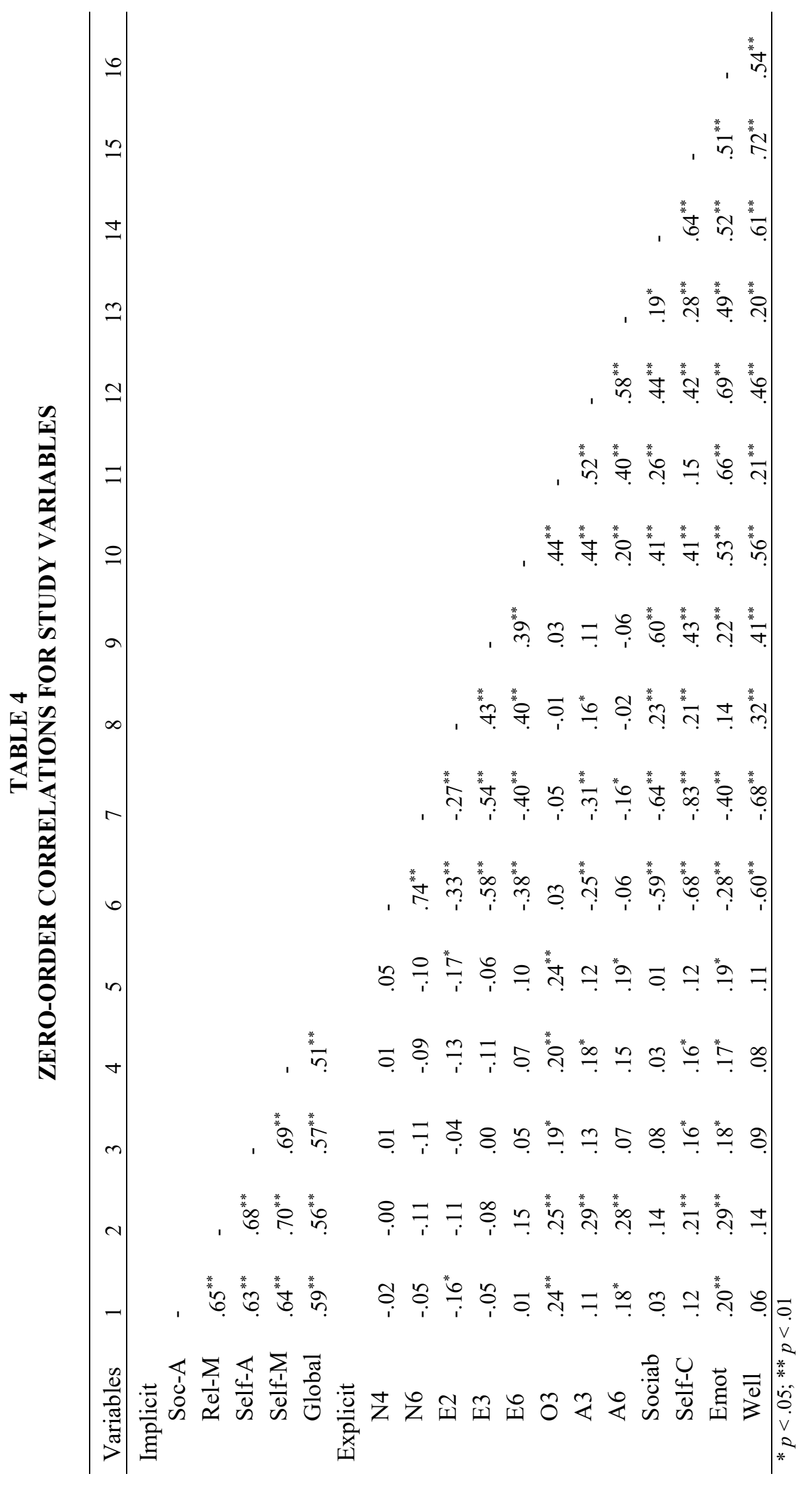


Widaman (1985) recommends comparing model fit statistics for a set of nested, progressively restrictive CFA models to assess the convergent and discriminant validity of alternative measures. In the initial, least restrictive model (Model 1; see Figure 2) there are two freely correlated method factors and four freely correlated EI trait factors. Model 2 is more restrictive in that it contains only two freely correlated method factors and no EI trait factors. Model 3 is more restrictive in that it constrains the EI trait factors to be perfectly correlated (i.e., a single latent EI trait). Finally, Model 4 contains four freely correlated EI trait factors and two uncorrelated method factors. An a priori power analysis (MacCallum et al., 1996) indicated that the sample exceeded the number required to attain adequate power (.80), given a null hypothesis of close fit $\left(\mathrm{H}_{0}: \mathrm{RMSEA}=.05\right)$ and an alternative hypothesis of poor fit $\left(\mathrm{H}_{\mathrm{A}}: \mathrm{RMSEA}=.10\right)$.

The first comparison (Model 1 vs Model 2) demonstrates convergent validity to the extent that deterioration occurs (i.e., poorer fit statistics for Model 2). The second model comparison (Model 1 vs Model 3) demonstrates discriminant validity to the extent the fit statistics for the perfectly correlated EI trait model (Model 3) are poorer than those for the least restrictive model. The final comparison (Model 1 vs Model 4) evaluates the independence of method factors. Given that the methods involve distinct cognitive processes (System 1 vs System 2), the method factors are expected to be uncorrelated, and a null finding for this comparison is predicted. Table 5 displays the fit statistics for each CFA model.

TABLE 5 SUMMARY OF GOODNESS-OF-FIT STATISTICS FOR CFA MODELS

\begin{tabular}{lccccc}
\hline \multicolumn{1}{c}{ Model } & $\chi^{2}$ & df & CFI & RMSEA & 90\%C.I. \\
\hline 1. Freely correlated traits; freely correlated methods & 174.22 & 95 & .95 & .069 & $.053, .085$ \\
2. No traits; freely correlated methods & 622.52 & 110 & .69 & .164 & $.151, .176$ \\
3. Perfectly correlated traits; freely correlated methods & 390.44 & 108 & .84 & .123 & $.110, .136$ \\
4. Freely correlated traits; uncorrelated methods & 176.15 & 96 & .95 & .070 & $.053, .085$ \\
\hline
\end{tabular}

The results indicate that the least restrictive model (Model 1) fits the variance-covariance structure of the MTMM data very well. In accord with conventional recommendations, the CFI value is greater than .90 and the RMSEA is less than .08 (Bentler, 1990; Byrne, 2010). Additionally, the $90 \%$ confidence interval for the RMSEA statistic is quite narrow and the upper bound falls below the threshold for a poor fit recommended by MacCallum et al. (1996). The fit statistics for Model 2 and Model 3 are considerably worse than those of for Model 1 and both fall well beyond the conventional thresholds for good fit (CFA < .90 ; RMSEA > .10). On the other hand, the fit statistics for Model 4 are virtually identical with those for Model 1, indicating a good fit. Table 6 displays the statistical comparisons among the models. The significant, substantial deterioration of the fit statistics for the more restrictive models (Model 2 and Model 3) provide support for both the convergent and discriminant validity of the measures.

\section{TABLE 6 DIFFERENTIAL GOODNESS-OF-FIT STATISTICS FOR NESTED MODEL COMPARISONS}

\begin{tabular}{lcrc}
\hline Model Comparisons & $\Delta \chi^{2}$ & df & $\Delta$ CFI \\
\hline Test of Convergent Validity & & & \\
$\quad$ Model 1 vs. Model 2 & $448.3^{*}$ & 15 & .26 \\
Tests of Discriminant Validity & & & \\
Model 1 vs. Model 3 & $216.12^{*}$ & 13 & .11 \\
Model 1 vs. Model 4 & 1.93 & 1 & .01 \\
\hline
\end{tabular}

Table 7 displays the loadings for each observed measure on the four EI trait factors and the two method factors of Model 1. The results demonstrate that most of the indicator variables for each factor had significant loadings (28 out of 36), providing further support for the construct validity of the measures. 
TABLE 7

TRAIT AND METHOD LOADINGS FOR CFA MODEL 1

\begin{tabular}{|c|c|c|c|c|c|c|}
\hline & $\begin{array}{l}\text { Self- } \\
\text { Awareness }\end{array}$ & $\begin{array}{l}\text { Self- } \\
\text { Management }\end{array}$ & $\begin{array}{l}\text { Relationship } \\
\text { Management }\end{array}$ & $\begin{array}{l}\text { Social } \\
\text { Awareness }\end{array}$ & Implicit & Explicit \\
\hline \multicolumn{7}{|l|}{ Implicit } \\
\hline \multicolumn{7}{|l|}{ Measures } \\
\hline Self-Aware & -.048 & & & & $.828^{* * *}$ & \\
\hline Self-Mgt & & -.051 & & & $.819^{* * * *}$ & \\
\hline Relation-Mgt & & & .004 & & $.832^{* * *}$ & \\
\hline Social-Aware & & & & -.010 & $.785^{* * *}$ & \\
\hline Global-EI & $.322^{* * *}$ & $-.193^{*}$ & $-.348^{* * *}$ & -.026 & $.665^{* * *}$ & \\
\hline \multicolumn{7}{|l|}{ Explicit } \\
\hline \multicolumn{7}{|l|}{ Measures } \\
\hline E6PosEmotion & $.525^{* * *}$ & & & & & $.514^{* * *}$ \\
\hline O3Feelings & $.784^{* * *}$ & & & & & -.010 \\
\hline Emotionality & $.733^{* * *}$ & $-.268^{* * *}$ & & & & $.244^{* *}$ \\
\hline Wellbeing & $.276^{* * *}$ & $\begin{array}{l}-.509^{* * * *} \\
.487^{* * *}\end{array}$ & & & & $\begin{array}{l}.584^{* * *} \\
-.653^{* * *}\end{array}$ \\
\hline \multicolumn{7}{|l|}{ N4SelfConscious } \\
\hline N6Vulnerable & & $.699^{* * *}$ & & & & $-.599^{* * *}$ \\
\hline Self-Control & & $-.773^{* * *}$ & -.071 & & & $485^{* * *}$ \\
\hline E2Gregarious & & & $-.543^{* * *}$ & & & $.721^{* * *}$ \\
\hline E3Assertive & & & $.267^{* *}$ & & & $.798^{* * *}$ \\
\hline Sociability & & & $.437^{* * *}$ & $.464^{* * *}$ & & $.610^{* * *}$ \\
\hline A3Altruism & & & & $.790^{* * *}$ & & .150 \\
\hline 6Tenderminded & & & & $.731^{* * *}$ & & -.118 \\
\hline
\end{tabular}

\section{DISCUSSION}

The purpose of this research was to investigate the construct validity of implicit measures designed to assess attributes related to trait emotional intelligence. More specifically, this study sought to build upon previous research by developing IATs of trait-EI that are less contaminated by measurement error and have better psychometric properties than those developed by Oberdiear et al. (2016). Unlike Oberdiear's IATs, this study's IATs all had reliability coefficients that fall within the range that is generally considered adequate (Nunnally, 1978). The improvements in reliability were likely a result of improvements in overall stimulus classification error rates. The average error rates for stimuli misclassification dropped from about $11 \%$ to $7 \%$. However, these average error rates remain greater than the average error rates for IATs targeting racial attitudes (obtained from the Project Implicit web site) which range from $4 \%$ to $6 \%$, suggesting that there is still room for improvement.

Overall, the results supported the construct validity of the measures. However, despite this success, it is important to note that none of the four component IATs exhibited substantial, significant loadings on their corresponding latent EI trait factors. Although the global IAT had non-trivial loadings on three of the four latent traits, the values represent moderate relationships according to Cohen's (1998) standards for effect magnitude. This result is due in part to the lack of substantial correlations between the implicit and explicit measures. Of the 60 correlations in the heterotrait-heteromethod rectangle of the MTMM correlation matrix, only 20 were significant.

Previous research found the two IATs involving the emotional recognition factors (Self-awareness and Social Awareness) had significant loadings on their respective latent trait factors (Oberdiear et al., 2016). These results suggest that our implicit and explicit identities are less concordant when it comes to both the way we view ourselves managing and expressing emotions. This dissociation may indicate a potential for 
implicit measures to have incremental validity (relative to explicit measures) for the prediction of overt behavior related to these constructs (i.e., effectively managing our own and others' emotions at work). Regardless, the hypothesized CFA model clearly captured the variance-covariance structure of the 17 observed variables according to fit statistics. Comparisons between the initial model and subsequent restricted models (e.g., a single EI trait factor in addition to the two method factors) exhibited substantial deterioration in fit statistics and evidence of convergent and discriminant validity for the measures.

It is important to note some concerns with using MTurk workers for a HIT that involves tasks like this study requires. IAT stimulus error rates identify invalid scores in a way that conventional self-report measures typically lack. Using this method, we found evidence that $46 \%$ of the original subject pool (i.e., those who completed all measures within the time constraints) did not conscientiously perform their HIT. For research that relies on MTurk workers this constitutes a huge problem. For example, the reliability of the IAT for Self-Awareness would have fallen from .74 to .55 if we had not been able to identify these subjects and we would have been led to an invalid conclusion regarding the likely psychometric properties of the measure. Researchers using MTurk should endeavor to incorporate validity checks for the manipulations in their studies to assess internal validity concerns.

Finally, there are some clear implications for future research. We need to develop experimental manipulations and field studies that provide subjects opportunities to exhibit behavior related to emotional intelligence so that we can explore the predictive validity of explicit and implicit measures. If the results of the research involving social attitudes is indicative of what we can expect in this domain, then explicit and implicit measures will differentially predict relevant behavior. The question remains, what behaviors do the explicit and implicit measures differentially predict?

\section{ENDNOTE}

1. The authors wish to acknowledge the contributions of research team members Hayley Barry, Tony Crowder, Michaela Fisher, Brad Soza, Jakob Hull and Elizabeth Troutwine in making this research possible and we express our gratitude for their help.

\section{REFERENCES}

Bentler, P.M. (1990). Comparative fit indexes in structural models. Psychological Bulletin, 107, 238-246. Byrne, B.M. (2010). Structural Equation Modeling with AMOS (Second Edition). New York: Routledge.

Campbell, D.T., \& Fiske, D.W. (1959). Convergent and discriminant validation by the multitraitmultimethod matrix. Psychological Bulletin, 56, 81-105.

Cherniss, C. (2010). Emotional intelligence: Toward clarification of a concept. Industrial and Organizational Psychology, 3, 110-126.

Costa, P.T., \& McCrae, R.R. (1992). NEO PI-R Professional Manual. Odessa, FL: Psychological Assessment Resources, Inc.

Fazio, R., \& Olsen, M. (2003). Implicit measures in social cognition research. Annual Review of Psychology, 54, 297-327.

Goleman, D.P. (1995). Emotional Intelligence: Why It Can Matter More Than IQfor Character, Health and Lifelong Achievement. Bantam Books, New York.

Goleman, D. (2001). An EI-based theory of performance. The Emotionally Intelligent Workplace: How to Select for, Measure, and Improve Emotional Intelligence in Individuals, Groups, and Organizations, 1, 27-44.

Greenwald, A., \& Banaji, M. (1995). Implicit social cognition: Attitudes, self-esteem, and stereotypes. Psychological Review, 102, 4-27.

Greenwald, A., Banaji, M., Rudman, L., Farnham, S., Nosek, B., \& Mellot, D. (2002). A unified theory of implicit attitudes, stereotypes, self-esteem, and self-concept. Psychological Review, 109(1), 3-25. 
Greenwald, A.G., Nosek, B.A., \& Banaji, M.R. (2003). Understanding and using the Implicit Association Test: I. An improved scoring algorithm. Journal of Personality and Social Psychology, 85(2), 197-216. doi:10.1037/0022-3514.85.2.197

Kahneman, D. (2011). Thinking, Fast and Slow. New York: Macmillan Publishers.

Lane, K.A., Banaji, M.R., Nosek, B.A., \& Greenwald, A.G. (2007). Understanding and Using the Implicit Association Test: IV: What We Know (So Far) about the Method. In B. Wittenbrink \& N. Schwarz (Eds.), Implicit measures of attitudes (pp. 59-102). New York: Guilford Press.

Lievens, F., \& Chan, D. (2010). Practical intelligence, emotional intelligence, and social intelligence. In Farr, \& Tippins (Eds.), Handbook of employee selection (pp. 231-337). NY: Routledge.

MacCallum, R.C., Browne, M.W., \& Sugawara, H.M. (1996). Power analysis and determination of sample size for covariance structure modeling. Psychological Methods, 1(2), 130.

Mayer, J.D., Salovey, P., \& Caruso, D.R. (2004). Emotional intelligence: Theory, findings, and implications. Psychological Inquiry, 15(3), 197-215.

Nosek, B., Greenwald, A., \& Banaji, M. (2005). Understanding and using the Implicit Association Test: II. Method variables and construct validity. Personality and Social Psychology Bulletin, 31(2), $166-180$.

Nunnally, J. (1978). Psychometric theory. New York: McGraw-Hill.

Oberdiear, L., Fischer, D., Fiscus, T., Willis, D., Stassen, M., \& Miles, A. (2016, May). Development and Validation of Implicit Measures of Emotional Intelligence. Paper presented at the 28th annual meeting of the Association for Psychological Science, Chicago, IL.

Petrides, K.V. (2011). Ability and Trait Emotional Intelligence. In T. Premuzic, S. Stumm, \& A. Furnham (Ed.), The Wiley-Blackwell Handbook of Individual Differences.

Petrides, K.V., \& Furnham, A. (2001). Trait emotional intelligence: Psychometric investigation with reference to established trait taxonomies. European Journal of Personality, 15(6), 425-448.

Petrides, K.V., \& Furnham, A. (2003). Trait emotional intelligence: Behavioural validation in two studies of emotion recognition and reactivity to mood induction. European Journal of Personality, 17, $39-57$.

Petrides, K.V., Pita, R., \& Kokkinaki, F. (2007). The location of trait emotional intelligence in personality factor space. British Journal of Psychology, 98(2), 273-289.

Schnabel, K., Asendorpf, J., \& Greenwald, A. (2008). Understanding and using the Implicit Association Test: V. Measuring semantic aspects of trait self-concepts. European Journal of Personality, pp. 695-706.

Steffens, M., Kirschbaum, M., \& Glados, P. (2008). Avoiding stimulus confounds in Implicit Association Tests by using the concepts as stimuli. (2008). British Journal of Social Psychology, 47(2), 217 243.

Widaman, K.F. (1985). Hierarchically nested covariance structure models for multi-trait multi- method data. Applied Psychological Measurement, 9, 1-26.

Wilson, T., \& Dunn, E. (2004). Self-knowledge: Its limits, value, and potential for improvement. Annual Review of Psychology, 55, 493-518.

Wilson, T.D., Lindsey, S., \& Schooler, T.Y. (2000). A model of dual attitudes. Psychological Review, 107, 101-126. 